\title{
Evidence that Extreme Dilutions of Paclitaxel and Docetaxel Alter Gene Expression of In Vitro Breast Cancer Cells
}

\author{
Sinem Şeker ${ }^{1}$ Celal Güven ${ }^{2}$ Handan Akçakaya ${ }^{3} \quad$ Nurten Bahtiyar $^{4}$ Fahri Akbaş ${ }^{5}$ ilhan Onaran ${ }^{1}$
}

${ }^{1}$ Department of Medical Biology, Istanbul University, Cerrahpaşa

Address for correspondence Ilhan Onaran, PhD, Cerrahpaşa Medical Faculty of Medicine, Istanbul, Turkey

2 Department of Biophysics, University of Adiyaman, Faculty of Faculty, Department of Medical Biology, Cerrahpaşa 34098 Fatih-Istanbul, Turkey (e-mail: onaran.il@gmail.com;

Medicine, Adiyaman, Turkey

${ }^{3}$ Department of Biophysics, Istanbul University, Istanbul Faculty of ilonaran@istanbul.edu.tr).

Medicine, Istanbul, Turkey

${ }^{4}$ Department of Biophysics, Istanbul University, Cerrahpaşa Faculty of Medicine, Istanbul, Turkey

${ }^{5}$ Department of Medical Biology, Faculty of Medicine at Bezmialem Vakif University, Istanbul, Turkey

Homeopathy 2018;107:32-39.

\begin{abstract}
\section{Keywords}

- homeopathy

- gene expression

- taxane

- paclitaxel

- docetaxel

- MCF-7

Background Gene expression analysis of cells treated with extreme dilutions or micro amounts of drugs has been used to provide useful suggestions about biological responses. However, most of the previous studies were performed on medicines being prepared from a variety of herbal and metal sources. This study investigated the effects of ultramolecular dilution of the taxane anti-cancer drugs, which are not commonly used in homeopathic medicines, on mRNA expression profiles of five key genes ( $p 53$, p21, COX-2, TUBB2A and TUBB3) in the breast cancer cell line MCF-7.

Method MCF-7 cells were exposed to paclitaxel (Taxol) or docetaxel (Taxotere) preparations (6X, 5C and $15 \mathrm{C}$ dilutions prepared from pharmacological concentration of $25 \mathrm{nmol} / \mathrm{L}$ ) for 72 hours. The cell culture groups were evaluated with the trypan blue dye exclusion method for the proliferation/cytotoxicity rates, immuno-staining $\beta$-tubulin for microtubule organization, and reverse transcription polymerase chain reaction for gene expression levels. Fold-change in gene expression was determined by the $\Delta \Delta \mathrm{Ct}$ method.

Results The administration of diluted preparations had little or no cytotoxic effect on MCF-7 cells, but altered the expression of genes analyzed with a complex effect. According to the $\Delta \Delta \mathrm{Ct}$ method with a five-fold expression difference $(p<0.05)$ as a cutoff level, ultra-high dilutions of paclitaxel and docetaxel showed differential effects on the studied genes with a concentration-independent activity. Furthermore, the dilutions disrupted the microtubule structure of MCF-7 cells, suggesting that they retain their biological activity.

Conclusion Despite some limitations, our findings demonstrate that gene expression alterations also occur with ultra-high dilutions of taxane drugs.
\end{abstract}

received

October 17, 2016

accepted

December 4, 2017

published online

January 23, 2018
Copyright @ 2018 The Faculty of Homeopathy
DOI https://doi.org/ 10.1055/s-0037-1618585. ISSN $1475-4916$. 


\section{Introduction}

For many years it has been known that many genetic regulatory reactions occur at extremely low intracellular concentrations of the nanomolar scale. Studies in the 1990s also demonstrated that environmental stress such as extremely low-dose ionizing radiation and frequency electromagnetic field may influence gene expression. ${ }^{1,2}$ In recent decades, evidence from previous studies of several independent groups with different substances, dilutions and experimental designs demonstrated that high and extreme dilutions could alter expression levels of various genes in cells in vitro, ${ }^{3-8}$ though data from some other studies were not consistent with these findings. ${ }^{9,10}$ To our knowledge, most of the studies that focused on gene expression have been conducted with medicines being prepared from a variety of herbal and metal sources.

As known, synthetic and semi-synthetic compounds might be used according to the homeopathic criteria for therapeutic purposes. Taxanes, that is, paclitaxel (Taxol) and docetaxel (Taxotere) and taxane homologs are presently considered as the most effective group of plant-derived chemotherapeutic agents. Paclitaxel is obtained via a semisynthetic process from Taxus baccata and docetaxel is a semi-synthetic analogue of Taxol. They contain a complex taxane ring with an ester on the $\mathrm{C}-13$ position, and the moieties at the $\mathrm{C}-2^{\prime}$ and $\mathrm{C}-3^{\prime}$ positions on the side chain of C-13 are necessary for their anti-microtubule activity. Docetaxel is different from paclitaxel at two sites: a hydroxyl group on C-10 instead of the acetate ester in paclitaxel, and a tert-butyl carbamate ester on the side chain of phenyl propionate.

Taxanes are active against a range of human cancers, such as non-small cell lung cancer, ovarian, breast, gastric, prostate and head-and-neck cancers, and are the first-choice drugs for treating various metastatic cancers. Their antitumor activity is based on stabilization of the microtubule dynamics and thereby disruption of the cell cycle. However, paclitaxel and docetaxel also cause some serious side effects. According to the literature, neither drug is used according to the homeopathic criteria. It has been shown that the concentrations within the range of $\mu \mathrm{mol} / \mathrm{L}$ to $\mathrm{nmol} / \mathrm{L}$ of these drugs could alter mRNA and microRNA expression levels of various genes in cancer cells in vitro. ${ }^{11-18}$ The studies demonstrated that most mRNAs and microRNAs were either up-regulated or down-regulated in a concentration- and time-dependent manner by taxane treatment of various cancer cell lines including human breast cancer cell line MCF-7. Given the knowledge that many genetic regulatory reactions occur at extremely low concentrations, gene expression data from tumor cells treated with extremely low doses or high dilution of taxanes may provide useful suggestions about biological responses of cells to anti-cancer treatment. However, to our knowledge, there is no literature describing whether extremely diluted solutions of taxanes affect gene expression, although there are several scientific studies that address the effects of diluted conventional drugs on gene expression.
Based on the above considerations, we analyzed the effects of the homeopathic concentrations of paclitaxel and docetaxel, including two below (6X and 5C) and one above Avogadro's limit (15C), on mRNA expression profiles of several key genes involved in cell growth control and carcinogenesis, in context to their cytotoxic effects. The starting concentration selected for testing was $25 \mathrm{nmol} / \mathrm{L}$ paclitaxel or docetaxel as related to pharmacological concentration and previous in vitro studies. ${ }^{11-13}$ Five genes, namely p53 (tumor protein p53 [TP53], NM_000546), p21 (cyclin-dependent kinase inhibitor 1A, NM_078467), COX-2 (prostaglandinendoperoxide synthase 2, NM_000963), TUBB2A (class IIa b-tubulin, NM_001069) and TUBB3 (class III b-tubulin, NM_006086), which have critical roles in regulation of tumor cell proliferation, survival, inflammation and angiogenesis, were selected as the target genes from among those showing up- or down-regulation at pharmacological doses of taxanes, according to earlier studies. ${ }^{13-15}$ On the other hand, we also evaluated the effects of these concentrations of both drugs on microtubule organization and cell cytotoxicity.

\section{Materials and Methods}

\section{Materials and Preparation of Drug Dilutions}

Paclitaxel (Taxol) and docetaxel (Taxotere) were purchased from Bristol-Myers Squibb Co. (Princeton, New Jersey, United States) and Aventis Pharma SA (Paris, France), respectively. Since taxanes are largely insoluble in water, the mother stock (25 nmol/L) and dynamized dilutions (6X, 5C and $15 \mathrm{C}$, which correspond to approximately final concentrations of $25 \times 10^{-15}, 25 \times 10^{-19}$ and $25 \times 10^{-39} \mathrm{~mol} / \mathrm{L}$ of taxanes), were prepared in high-performance liquid chromatography (HPLC) grade ethanol, using ratios of 1:10 (X potency series) or 1:100 (C potency series) and according to the standard homeopathic procedures. Briefly, paclitaxel or docetaxel was diluted 10 and 100 times in ethanol to obtain the $1 \mathrm{X}$ and $1 \mathrm{C}$ in sterile conditions, respectively. Subsequent serial $10 \times$ and $100 \times$ dilutions up to $6 \mathrm{X}$ and $15 \mathrm{C}$, each followed by vigorous mechanical shaking (20 strokes/s for 7.5 seconds), were then prepared in the same solvent using sterile glass test tubes and sterile filter tips with a polyethylene filter. Each test solution was added to the culture medium in a volume of $10 \mu \mathrm{L}$ in a total incubation medium of $2 \mathrm{~mL}$.

\section{Cell Cultures and Treatments}

MCF-7 cells, a human breast adenocarcinoma cell line, were cultured in Dulbecco's modified Eagle's medium supplemented with $10 \%$ heat-inactivated fetal calf serum and $1 \%$ pen-strep. Paclitaxel or docetaxel (6X,5C, 15C dilutions) or placebo $(0.5 \% \mathrm{v} / \mathrm{v}$ of absolute alcohol in a final volume of $2 \mathrm{~mL}$ as vehicle for the drugs) as a control was added to the culture media including MCF-7 cells $\left(1 \times 10^{5} / \mathrm{mL}\right)$ for 72 hours. In addition, untreated cells to evaluate a possible effect of ethanol on the cells served as the negative control. At the end of 72 hours, cells were harvested using the lysis buffer provided by RNA extraction kit and stored at $-80^{\circ} \mathrm{C}$. There were four wells for each of the treatments, and the experiment was repeated three times. 


\section{Cell Viability and Growth}

The viability of the MCF-7 cells was evaluated by trypan blue dye exclusion assay, which is used to determine the number of live and dead cells. Following exposure to drug dilutions, cells in medium were mixed with an equal volume of $0.2 \%$ trypan blue, and the number of cells excluding the dye was scored using a hemocytometer. The number of viable cells was calculated as percentage of the untreated cells, assuming that these were $100 \%$ viable.

The effect of the taxane dilutions on cell proliferation was also estimated by using trypan blue dye exclusion assay. Before and after exposure to drug dilutions, the number of viable cells per well was determined by counting, and the level of cell proliferation was expressed as a percentage relative to untreated cells.

\section{RNA Isolation and Real-Time Quantitative RT-PCR}

For the isolation of the total RNA, MCF-7 cells were cultured in four wells for each of the treatment and the total RNA was extracted using total RNA extraction kit (Thermo). The concentration of the extracted RNA was determined by spectrophotometric analysis (Multiskan GO, Thermo). Purified RNA (500 ng) was used for cDNA synthesis using RevertAid First Strand cDNA synthesis kit (Thermo Scientific) according to the manufacturer's instructions. Reverse transcription polymerase chain reaction (RT-PCR) was done using primers specific for p53, p21, COX-2, TUBB2A and TUBB3 genes. Specific PCR primers were designed using primer3 software (http://primer3plus.com/). The primer sequences of the genes are given below.

P53: Forward 5' - TCCACTACAACTACATGTGTAAC - 3'

Reverse 5' - GTGAAATATTCTCCATCCAGTG - 3'

P21: Forward 5' - GCAGACCAGCATGACAGATTT - 3'

Reverse 5' - GTGAAATATTCTCCATCCAGTG - 3'

COX-2: Forward 5' - GGTCTGGTGCCTGGTCTGATGATG - 3'

Reverse $5^{\prime}$ - GTCCTTTCAAGGAGAATGGTGC - 3'

TUBB2A: Forward 5' - TTGTGTTCGGTCAGAGTGGT - 3'

Reverse 5' - GACTCCTTCCTCACCACATC - 3'

TUBB3: Forward 5' - TTCTGGTGGACTTGGAACCTGGAA - $3^{\prime}$

Reverse 5' - TCACACTCTTTCCGCACGACATCT - 3'

Beta actin: Forward 5' - AACAAGAGGCCACACAAATAGG - 3'

Reverse 5' - CAGATGTACAGGAATAGCCTCCG - 3'

Quantitative analysis was performed by using the Fast SYBR Green Master Mix (Thermo). Reaction mixture contained a total volume of $20 \mu \mathrm{L}$. The PCR conditions were $95^{\circ} \mathrm{C}$ for 3 minutes, then 40 cycles of $95^{\circ} \mathrm{C}$ for 10 seconds and $60^{\circ} \mathrm{C}$ for 30 seconds. The relative amount of target mRNA in test sample was calculated and normalized to the corresponding $\beta$-actin mRNA transcript level as a housekeeping gene. All reactions were performed three times and the mean values were used. Transcriptional gene expression, which is subsequently referred to as gene expression, was defined as foldchange (FC) versus ethanol-treated controls and it was determined with the $\Delta \Delta \mathrm{Ct}$ method. ${ }^{19}$

\section{Immunofluorescence}

MCF-7 cells were exposed to immunofluorescence staining to observe microtubules. Briefly, primary cells were fastened with $2 \%$ paraformaldehyde in phosphate-buffered saline (PBS) for 20 minutes at room temperature. MCF-7 cells were permeabilized and blocked in PBS containing 0.1\% Triton X-100 and $5 \%$ fetal calf serum for 30 minutes. The primary antibody (anti- $\beta$ tubulin antibody, 1:200) was used at $4^{\circ} \mathrm{C}$ during the night. The secondary antibody, which was used at room temperature for 2 hours, was Alexa Fluor 488conjugated goat anti-rabbit IgG (1:200). Microtubules were visualized using streptavidin Alexa Fluor 488 conjugate $(1 \mathrm{mg} / \mathrm{mL})$ and nuclei in turn with 4', 6-diamidino-2-phenylindole (DAPI, Invitrogen Molecular Probes, Oregon, United States). All images were obtained on an Olympus BX51 Microscope equipped with DP72 camera, controlled by Olympus DP2-TWAIN software.

\section{Statistical Analyses}

The non-parametric Kruskal-Wallis test followed by Dunn's post-test for multiple comparisons was applied to test the significance of the various data collected during the study. The statistical significance was set at $p<0.05$ and a mean difference equal to or greater than $5 \mathrm{FC}$ in expression levels. The software used was GraphPad version 5.0 and values reported were means \pm SD.

\section{Results}

\section{Effect of Ultra-High Dilutions of Paclitaxel and Docetaxel on Cell Viability and Growth}

We first examined cytotoxic effects of three different dilutions $\left(6 \mathrm{X}, 5 \mathrm{C}\right.$, and $15 \mathrm{C}$; final concentrations: $25 \times 10^{-15}$, $25 \times 10^{-19}$ and $25 \times 10^{-39} \mathrm{~mol} / \mathrm{L}$ ) and pharmacological concentration $(25 \mathrm{nmol} / \mathrm{L})$ of paclitaxel or docetaxel on the growth and survival of MCF-7 cells. In this study, the cell viability and proliferation inhibition rates were reported as relative to the untreated cells to assess possible cytotoxic effects of ethanol alone as well as the associated concentrations.

As can be seen in -Table 1, $25 \mathrm{nmol} / \mathrm{L}$ paclitaxel or docetaxel induced significant increases in cell-death rate compared with untreated cells. Exposure of cells to the increasing dilutions of paclitaxel and docetaxel revealed less significant changes in cell-death rate that ranged from 9 to $12 \%$ and 11 to $15 \%$, respectively. Meanwhile, ethanol alone induced a cell-death rate very similar to the dilution

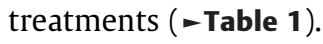

When MCF-7 cells were treated with different doses of drugs for 72 hours, the inhibition of cellular growth against the dose of $25 \mathrm{nmol} / \mathrm{L}$ of the drugs was more pronounced than with homeopathic concentrations. This concentration caused an approximately $97 \%$ reduction in cell proliferation. The addition of both taxanes significantly decreased cell proliferation of MCF-7 cells compared with untreated cells. Paclitaxel- and docetaxel-induced proliferation inhibition rates for the extreme doses ranged from 40 to $56 \%$ and 44 to $74 \%$, respectively ( - Table 1). Exposure to ethanol vehicle alone significantly inhibited cell proliferation to a similar extent as homeopathic doses of the drugs (except 6X treatment of docetaxel). 
Table 1 Effects of paclitaxel and docetaxel treatments (72 h) on cell viability and proliferation of human breast cancer cell line MCF-7

\begin{tabular}{|l|l|l|l|l|}
\hline & \multicolumn{2}{|c|}{ Paclitaxel } & \multicolumn{2}{c|}{ Docetaxel } \\
\hline In vitro treatment & $\begin{array}{l}\text { Cell viability } \\
\text { (\% of control) }\end{array}$ & Cell proliferation (\%) & $\begin{array}{l}\text { Cell viability } \\
\text { (\% of control) }\end{array}$ & Cell proliferation (\%) \\
\hline Ethanol & $92 \pm 5$ & $65 \pm 7$ & $92 \pm 5$ & $65 \pm 7$ \\
\hline $25 \mathrm{nmol} / \mathrm{L}$ & $2 \pm 1^{\mathrm{a}}$ & $3 \pm 1^{\mathrm{a}}$ & $3 \pm 1^{\mathrm{a}}$ & $2 \pm 1^{\mathrm{a}}$ \\
\hline $6 \mathrm{X}$ & $88 \pm 6$ & $54 \pm 6$ & $87 \pm 9$ & $26 \pm 4^{\mathrm{a}}$ \\
\hline $5 \mathrm{C}$ & $90 \pm 6$ & $62 \pm 6$ & $89 \pm 8$ & $49 \pm 5$ \\
\hline $15 \mathrm{C}$ & $91 \pm 6$ & $60 \pm 7$ & $85 \pm 12$ & $56 \pm 8$ \\
\hline
\end{tabular}

Note: Survival was expressed as the percentage of surviving cells relative to the untreated control cells (without drugs). Proliferation results are expressed as percent cell proliferation relative to the proliferation of control cells.

aSignificant difference compared with the ethanol group $(p<0.05)$.

\section{Effect of Ultra-High Dilutions of Paclitaxel and Docetaxel on Expression of Selected Five Genes}

To assess the effects of homeopathic doses of the taxanes on mRNA expression, relative gene expression differences of five selected genes ( $p 53, p 21, C O X-2, T U B B 2 A$, and TUBB3) between drug-treated and control cells (the corresponding ethanol or untreated controls) were examined by quantitative RT-PCR. We did not perform this analysis on the cells exposed to clinical dose due to a massive loss of cells because of death.

Comparison of the $2^{-\Delta \Delta \mathrm{Ct}}$ values calculated from measurement of the cells treated with ethanol and the dilution treatments showed to have an influence on gene expression of the dilution treatment ( - Tables 2 and 3, and - Fig. 1). Using a fivefold expression difference ( $p<0.05$ ) as a cut-off level, it was observed that the treatment with taxanes significantly changed the expression of a total 7 of 30 samples in context to the selected five genes ( $\mathbf{-}$ Tables $\mathbf{2}$ and $\mathbf{3}$ ). We also observed that all the examined genes except TUBB2A were significantly affected at some dilutions for paclitaxel treatment (-Table 2 and -Fig. 1A). Similarly, docetaxel treatment changed the expression of four genes except p53 at some dilutions (-Table 3 and -Fig. 1B). Changes in differential regulation with dilution treatments were quantitatively high, ranging from an up-regulation of approximately 23 (p21 gene at 15C paclitaxel) to a down-regulation of about -17 ( $p 21$ at $5 \mathrm{C}$ paclitaxel), and they were concentration independent. As can be seen in - Tables 2 and 3, and - Fig. 1, there were also a few differences in the expression profile of the investigated genes between docetaxel and paclitaxel treatments in the context of test dilutions. For example, $p 21$ level was up-regulated at $6 \mathrm{X}$ and $15 \mathrm{C}$ dilutions of paclitaxel, while it was down-regulated at $5 C$ dilution of both taxanes. Furthermore, TUBB3 gene was

Table $22^{-\triangle \Delta C T}$ values in mRNA expression of genes investigated in response to the MCF-7 cells treated in vitro with the ultra-diluted doses of paclitaxel for 72 hours

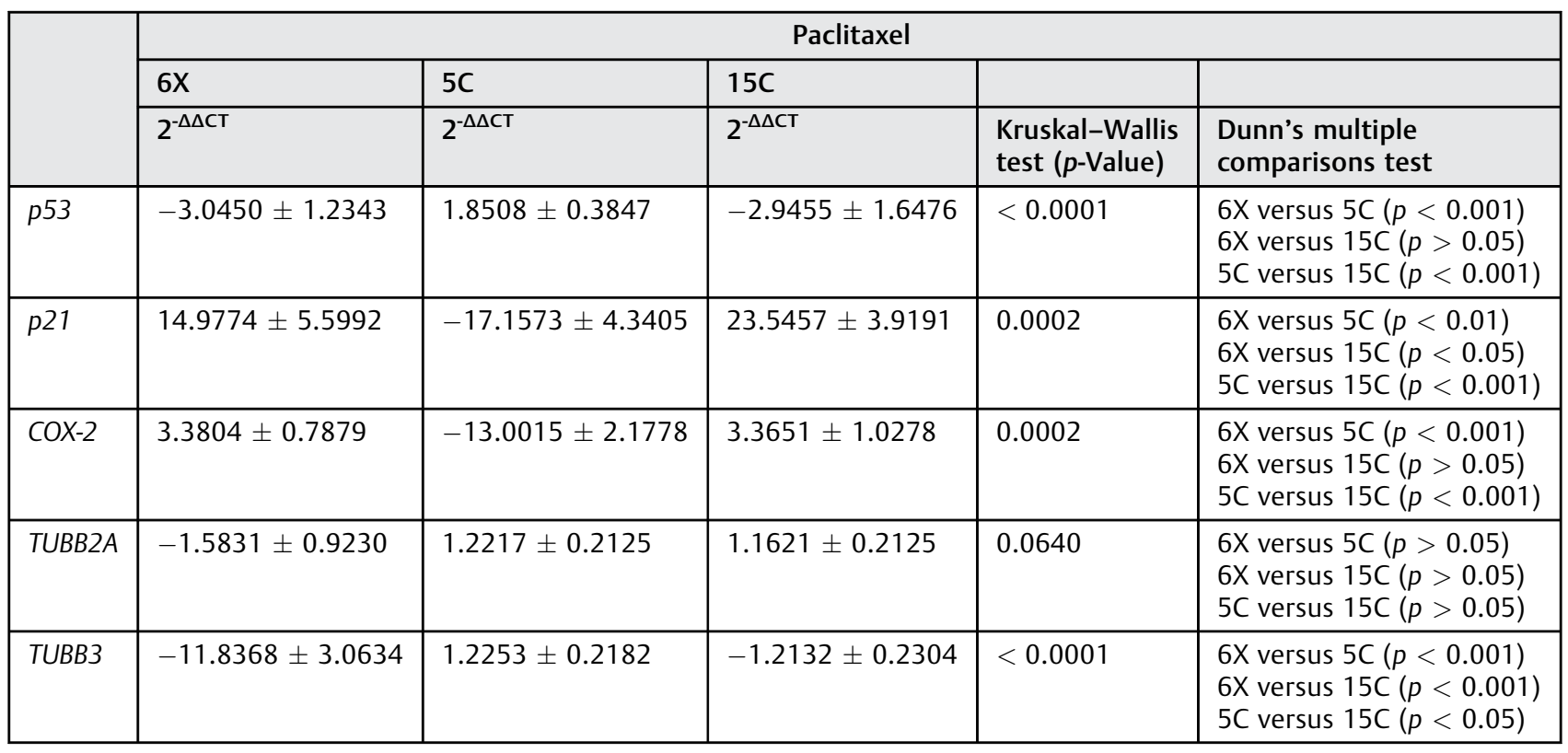

Note: The data are expressed as means \pm SD of fold-change relative to ethanol-treated series.

Abbreviation: SD, standard deviation. 
Table $32^{-\triangle \Delta C T}$ values in mRNA expression of genes investigated in response to the MCF-7 cells treated in vitro with the ultra-diluted doses of docetaxel for 72 hours

\begin{tabular}{|c|c|c|c|c|c|}
\hline & & & Docetaxel & & \\
\hline & $6 x$ & $5 C$ & $15 \mathrm{C}$ & & \\
\hline & $2^{-\Delta \Delta C T}$ & $2^{-\Delta \Delta C T}$ & $2^{-\Delta \Delta C T}$ & $\begin{array}{l}\text { Kruskal-Wallis } \\
\text { test ( } p \text {-Value) }\end{array}$ & $\begin{array}{l}\text { Dunn's multiple } \\
\text { comparisons test }\end{array}$ \\
\hline$p 53$ & $2.7204 \pm 1.0872$ & $3.8351 \pm 1.1799$ & $3.1821 \pm 1.7716$ & 0.5428 & $\begin{array}{l}6 X \text { versus } 5 C(p>0.05) \\
6 X \text { versus } 15 C(p>0.05) \\
5 C \text { versus } 15 C(p>0.05)\end{array}$ \\
\hline$p 21$ & $-1.6953 \pm 0.1972$ & $-3.5065 \pm 1.2518$ & $-1.2324 \pm 0.0852$ & 0.0004 & $\begin{array}{l}6 X \text { versus } 5 C(p<0.05) \\
6 X \text { versus } 15 C(p<0.05) \\
5 C \text { versus } 15 C(p<0.001)\end{array}$ \\
\hline $\operatorname{cox}-2$ & $1.2294 \pm 0.3485$ & $3.4240 \pm 0.9995$ & $-1.9387 \pm 0.5227$ & 0.0003 & $\begin{array}{l}6 X \text { versus } 5 C(p<0.01) \\
6 X \text { versus } 15 C(p>0.05) \\
5 C \text { versus } 15 C(p<0.001)\end{array}$ \\
\hline TUBB2A & $-6.3619 \pm 2.9636$ & $-3.5670 \pm 0.9047$ & $2.4751 \pm 0.2199$ & $<0.0001$ & $\begin{array}{l}6 X \text { versus } 5 C(p<0.001) \\
6 X \text { versus } 15 C(p>0.05) \\
5 C \text { versus } 15 C(p<0.001)\end{array}$ \\
\hline TUBB3 & $-2.6505 \pm 0.8173$ & $6.9884 \pm 1.5486$ & $-2.1173 \pm 0.4934$ & $<0.0001$ & $\begin{array}{l}6 X \text { versus } 5 C(p<0.001) \\
6 X \text { versus } 15 C(p>0.05) \\
5 C \text { versus } 15 C(p<0.001)\end{array}$ \\
\hline
\end{tabular}

Note: The data are expressed as means \pm SD of fold-change relative to ethanol-treated series.

Abbreviation: SD, standard deviation.

down-regulated by paclitaxel 6X dilution and up-regulated by docetaxel $5 C$ dilution. On the other hand, TUBB2A was the only significantly down-regulated gene at $6 \mathrm{X}$ dilution of docetaxel. In addition, only $\mathrm{COX}-2$ at paclitaxel $5 \mathrm{C}$-treated samples reached the significant threshold with down-regulation.

Relative gene expression differences were also quantified amongst the untreated reference cells and the dilution treatments. In this case, observed expression profile for the tested genes was different than those from measurement of the cells treated with ethanol and the dilution treatments (data not shown).

\section{Effect of Ultra-High Dilutions of Paclitaxel and Docetaxel on Microtubule Organization}

Since docetaxel and paclitaxel are microtubule-targeting agents, we also examined whether their homeopathic doses could perturb microtubule assembly in vitro and in cultured cells. After 72 hours exposure of ultra-low doses of both drugs, significant changes in microtubule organization were observed in response to these treatments. Representative images show progressive changes in microtubule morphology with ultra-low doses of both drugs in MCF-7 cells (-Fig. 2). However, no significant changes were found in ethanol-treated control cells.

\section{Discussion}

Studies published in recent years provide evidence that the action of taxanes on cells can alter the expression and modify the activity of numerous proteins; it also acts as a microtubule stabilizer. ${ }^{16,17,20,21}$ These studies mostly investigated possible effects within a range of concentrations from $\mu \mathrm{mol} / \mathrm{L}$ to $\mathrm{nmol} / \mathrm{L}$,
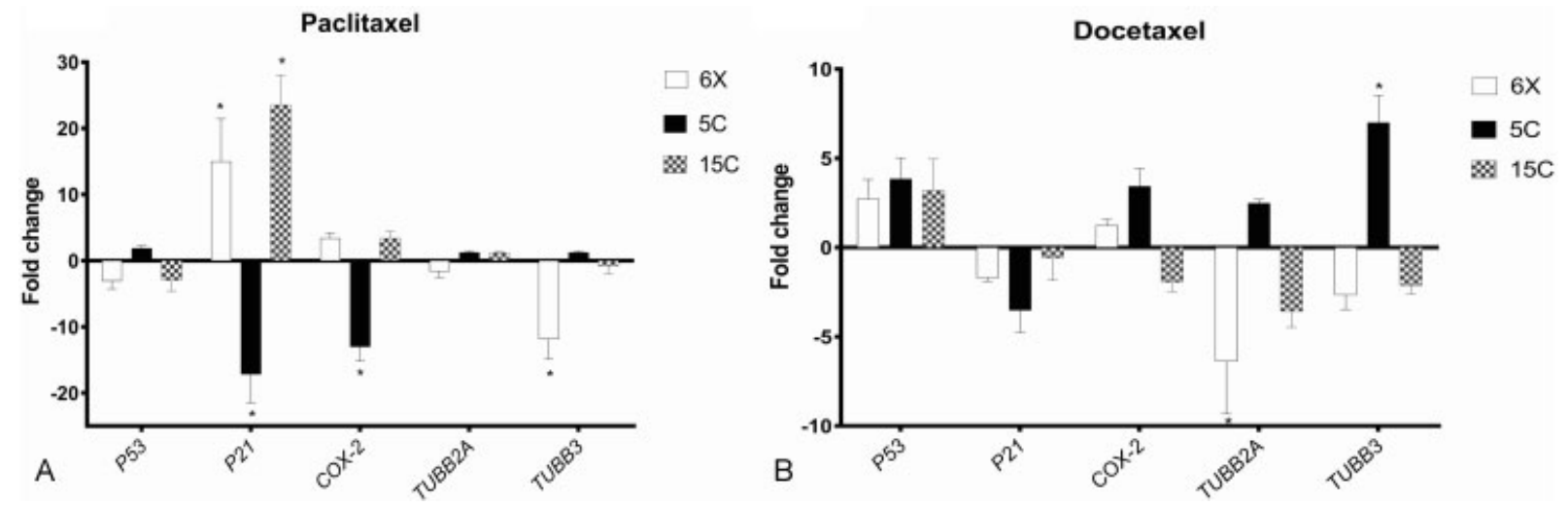

Fig. 1 Magnitude of fold-change in mRNA expression in response to ultramolecular dilution (6X,5C and 15C) of paclitaxel (A) and docetaxel (B) in MCF-7 cells treated for 72 hours. Expression levels are adjusted to $\beta$-actin for each sample and graphed as fold-changes relative to ethanoltreated cells. ${ }^{*} p<0.05$. 

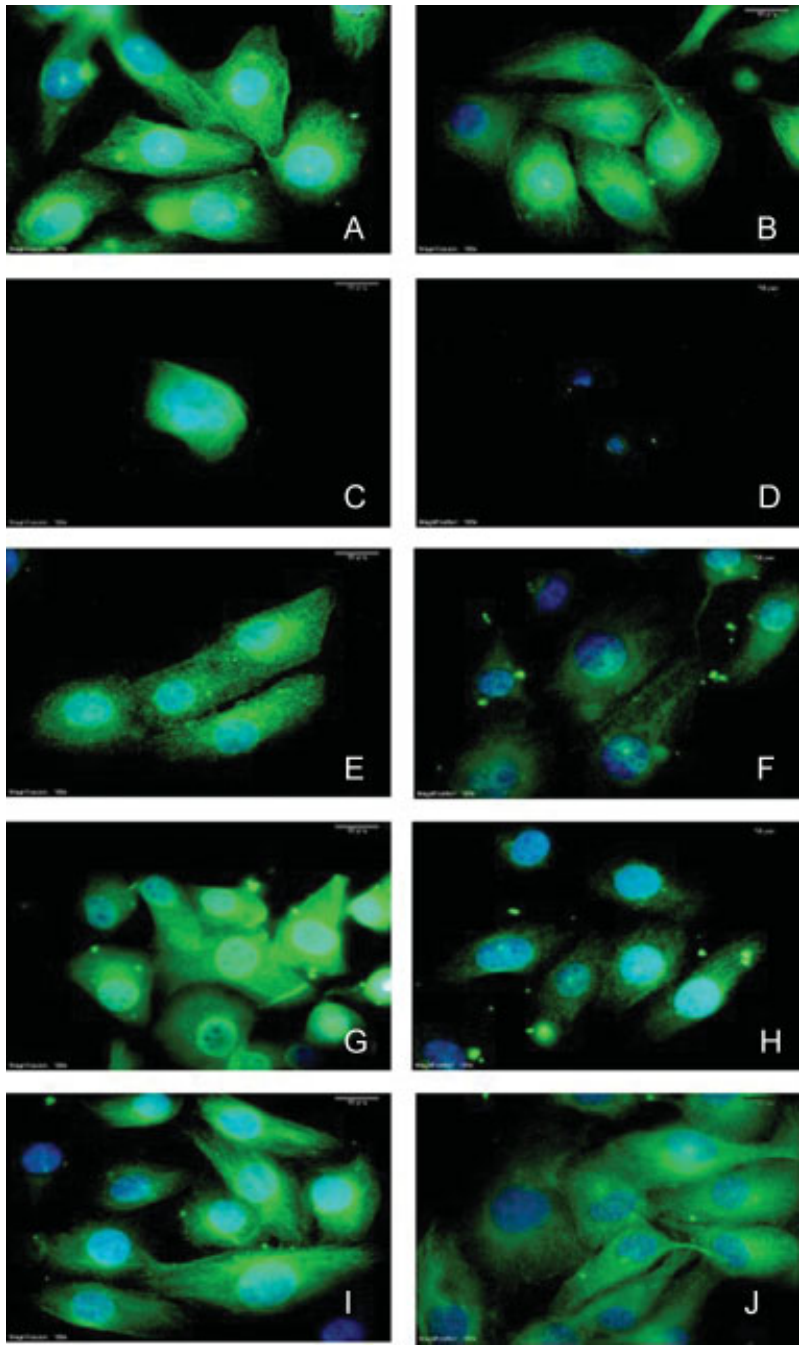

Fig. 2 Effect of 72 hours exposure to homeopathic concentrations of paclitaxel or docetaxel on microtubule organization. All the images are from the same experiment. (A) Control, (B) ethanol, (C) $25 \mathrm{nmol} / \mathrm{L}$ paclitaxel, (D) $25 \mathrm{nmol} / \mathrm{L}$ docetaxel, (E) 6X paclitaxel, (F) 6X docetaxel, (G) $5 \mathrm{C}$ paclitaxel, (H) 5C docetaxel, (I) 15C paclitaxel and (J) $15 \mathrm{C}$ docetaxel.

and showed that both the concentration and the exposure duration of taxanes are important to the response of cells. However, to our knowledge, there are no studies analyzing the effect of increasing dilutions of these drugs, which are not commonly used in homeopathic treatments, on gene expression. In this study, to evaluate whether extreme dilutions of paclitaxel and docetaxel alter gene expression of in vitro MCF-7 breast cancer cells, we selected five differentially expressed genes ( $p 53, p 21$, COX-2, TUBB2A, and TUBB3) detected in the earlier studies on taxanes. ${ }^{16,17,20,21}$ These genes are known to have critical roles in regulation of tumor cell proliferation, apoptosis, inflammation and angiogenesis. Taxanes most likely promote apoptosis by upregulating cyclindependent kinase inhibitor 1A (p21, Cip1) and tumor protein p53, which arrest the cell cycle. Taxanes are also known to have anti-inflammatory effects via inhibition of COX-2, the enzyme responsible for catalyzing the conversion of arachidonic acid into several different prostanoids, which are related to breast cancer carcinogenesis. Up-regulation of COX-2 gene was also associated with a worse breast cancer outcome. ${ }^{22}$ Tubulin is the major constituent of microtubules, which are dynamic polymeric structures consisting of heterodimers of $\alpha$-tubulins and $\beta$-tubulins. The cellular target with different affinity for taxanes has been identified as the $\beta$-subunit of tubulin. This binding suppresses the dynamics of mitotic spindle and induces mitotic arrest and apoptosis. Among $\beta$-tubulin isotypes, expression profiles of genes of the TUBB3 encoding class III $\beta$-tubulin and TUBB2A encoding class IIA $\beta$-tubulin were associated with tumorigenesis and response to taxanes. ${ }^{23}$

Homeopathic practitioners use potentized remedies diluted to both below and above Avogadro's limit, depending on the patient's symptoms. Therefore, we chose three potencies, 6X and 5C (below Avogadro's limit) and 15C (above Avogadro's limit). In this study, the starting concentration selected for testing was $25 \mathrm{nmol} / \mathrm{L}$ for both taxanes, since it was in the pharmacological range and a concentration that were shown by previous in vitro studies to have cytotoxic effects on breast cancer cells. ${ }^{11-20}$ According to this, the final concentrations of the diluted solutions in our culture conditions equate to approximately molar concentrations of $12.5 \times 10^{-17}, 12.5 \times 10^{-21}$ and $12.5 \times 10^{-41} \mathrm{~mol} / \mathrm{L}$ for both taxanes.

Our results on cell viability and growth showed that these taxane compounds at homeopathic concentrations and with the experimental approach used have slightly cytotoxic effects on MCF-7 cells. Present results provide evidence that the extreme dilutions (6X, 5C and 15C) of paclitaxel or docetaxel prepared from the concentrations of $25 \mathrm{nmol} / \mathrm{L}$ may alter gene expression in breast cancer cells in vitro, even when a five-fold expression difference was used as a cut-off level. As can be seen in - Tables 2 and $\mathbf{3}$ and - Fig. 1, gene expression analysis also clearly demonstrated that each drug dilution and comparison set had a distinct mRNA expression profile. Meanwhile, our study showed that vehicle (ethanol) alone could not elicit such an effect, as treatment of MCF-7 cells with ethanol did not change the expression profile of the tested genes as compared with the cells treated with untreated cells (data not shown).

Interestingly, $10^{-6}, 10^{-10}$ and $10^{-30}$ dilutions of $25 \mathrm{nmol} / \mathrm{L}$ paclitaxel or docetaxel exerted a complex effect on gene expression profile. The relative differential expression observed in either up- or down-regulated genes did not correlate with the general pharmacological rule, which emphasizes the linear association between the concentration and the effect of a given drug. Furthermore, one of the most striking findings was also that low and high dilutions of the same drug exerted a different expression pattern as down-regulation or up-regulation for some genes. Several reports from a series of experiments conducted at the micromolar and nanomolar scale consistently showed that mRNA expression responses to taxanes may vary depending on drug concentration. ${ }^{14,24}$ On the other hand, there are also a few reports indicating that some genes were regulated in opposite directions by mother tincture and by homeopathic solutions, according to the laws of hormesis. ${ }^{25,26}$ In our 
study, a 72-hour exposure of MCF-7 cells to mother tincture of $25 \mathrm{nmol} / \mathrm{L}$ induced massive cell death that precluded gene expression analysis. For this reason, it is not possible to say with certainty whether hormetic responses are operative with opposite behavior at different concentrations of our drugs of interest. Therefore, additional experiments are necessary to establish the precise mechanism underlying this phenomenon.

In addition, gene expression patterns induced by the same dilution of paclitaxel and docetaxel were different for any gene. Docetaxel, which is the second-generation semi-synthetic drug, differs at two positions from paclitaxel. Therefore, these findings may suggest that taxanes did not only affect the gene expression, but also that the effect of each structurally different taxane was different from the other in genetic expression profiling. This is not entirely a surprise since it has been found that paclitaxel and docetaxel show differential effects on various genes. ${ }^{15,27}$

Docetaxel and paclitaxel are known to drastically affect cell internal structures, especially nucleus and microtubule organization by stabilizing GDP-bound tubulin in the microtubule. ${ }^{28,29}$ Therefore, we also examined microtubule organization by immuno-staining $\beta$-tubulin to evaluate the biological effects at homeopathic dilutions of both agents. We report here that administration of $6 \mathrm{X}, 5 \mathrm{C}$ and $15 \mathrm{C}$ dilutions to MCF-7 cells disrupts microtubule dynamics. However, such an effect on ethanol-treated control cells was not observed. Therefore, our findings demonstrate that even extreme homeopathic dilutions of taxanes may have biological effects on breast cancer cells.

The present study necessarily has several limitations. First, we focused on the expression profile of five key genes. However, other gene(s), along with the genes investigated in this study, might be also regulated by extreme dilutions of taxanes. Second, we did not perform this analysis on the cells exposed to pharmacological concentrations, because cell death was induced even at these lower concentrations. In addition, no higher potencies than $15 \mathrm{C}$ have been evaluated.

\section{Conclusion}

Despite some limitations, our study shows that gene expression alterations also occur at concentrations much lower than those associated with pharmacological responses of taxanes and that high dilutions (homeopathic doses) of paclitaxel and docetaxel exerted complex effects on the expression of genes analyzed. Our results also suggest that even extremely diluted solutions of taxanes may have biological effects on breast cancer cells, although they are not cytotoxic.

\section{Conflict of Interest \\ None.}

\section{Acknowledgment}

This work was supported by the research fund of the University of Istanbul (Project number: 39256).

\section{References}

1 Ding LH, Shingyoji M, Chen F, et al. Gene expression profiles of normal human fibroblasts after exposure to ionizing radiation: a comparative study of low and high doses. Radiat Res 2005; 164:17-26

2 Goodman R, Wei LX, Xu JC, Henderson A. Exposure of human cells to low-frequency electromagnetic fields results in quantitative changes in transcripts. Biochim Biophys Acta 1989;1009:216-220

3 Sikdar S, Kumar Saha S, Rahman Khuda-Bukhsh A. Relative apoptosis-inducing potential of Homeopa-thic Condurango $6 \mathrm{C}$ and $30 \mathrm{C}$ in $\mathrm{H} 460$ lung cancer cells in vitro-Apoptosis-induction by homeopathic Condurango in H460 cells. J Pharmacopuncture 2014; 17:59-69

4 Sikdar S, Mukherjee A, Bishayee K, et al. Post-cancer treatment with Condurango 30C shows amelioration of benzo[a]pyreneinduced lung cancer in rats through the molecular pathway of Caspase-3-mediated apoptosis induction: anti-lung cancer potential of Condurango 30C in rats. J Pharmacopuncture 2013; 16:11-22

5 Olioso D, Marzotto M, Bonafini C, Brizzi M, Bellavite P. Arnica montana effects on gene expression in a human macrophage cell line. Evaluation by quantitative Real-Time PCR. Homeopathy 2016;105:131-147

6 Bigagli E, Luceri C, Dei A, Bernardini S, Dolara P. Effects of extreme dilutions of Apis mellifica preparations on gene expression profiles of human cells. Dose Response 2016;14:1559325815626685. doi: $10.1177 / 1559325815626685$

7 Bigagli E, Luceri C, Bernardini S, Dei A, Filippini A, Dolara P. Exploring the effects of homeopathic Apis mellifica preparations on human gene expression profiles. Homeopathy 2014;103:127-132

8 Marzotto M, Olioso D, Brizzi M, Tononi P, Cristofoletti M, Bellavite P. Extreme sensitivity of gene expression in human SH-SY5Y neurocytes to ultra-low doses of Gelsemium sempervirens. BMC Complement Altern Med 2014;14:104

9 Thangapazham RL, Gaddipati JP, Rajeshkumar NV, et al. Homeopathic medicines do not alter growth and gene expression in prostate and breast cancer cells in vitro. Integr Cancer Ther 2006; 5:356-361

10 Thangapazham RL, Rajeshkumar NV, Sharma A, et al. Effect of homeopathic treatment on gene expression in Copenhagen rat tumor tissues. Integr Cancer Ther 2006;5:350-355

11 Merlin JL, Barberi-Heyob M, Bachmann N. In vitro comparative evaluation of trastuzumab (Herceptin) combined with paclitaxel (Taxol) or docetaxel (Taxotere) in HER2-expressing human breast cancer cell lines. Ann Oncol 2002;13:1743-1748

12 Dai Y, Xie CH, Neis JP, Fan CY, Vural E, Spring PM. MicroRNA expression profiles of head and neck squamous cell carcinoma with docetaxel-induced multidrug resistance. Head Neck 2011; 33:786-791

13 Ziaja-Sołtys M, Rzymowska J. The determination of changes in the expression of genes for selected specific transcriptional factors in in vitro ductal breast cancer cells under the influence of paclitaxel. Cell Mol Biol Lett 2011;16:610-624

14 Panno ML, Giordano F, Mastroianni F, et al. Evidence that low doses of Taxol enhance the functional transactivatory properties of p53 on p21 waf promoter in MCF-7 breast cancer cells. FEBS Lett 2006;580:2371-2380

15 Sharma M, Tuaine J, McLaren B, et al. Chemotherapy agents alter plasma lipids in breast cancer patients and show differential effects on lipid metabolism genes in liver cells. PLoS One 2016;11: e0148049. doi: 10.1371/journal.pone.0148049

16 Hernández-Vargas H, Rodríguez-Pinilla SM, Julián-Tendero M, et al. Gene expression profiling of breast cancer cells in response to gemcitabine: NF-kappaB pathway activation as a potential mechanism of resistance. Breast Cancer Res Treat 2007; 102:157-172

17 Hernández-Vargas H, Palacios J, Moreno-Bueno G. Molecular profiling of docetaxel cytotoxicity in breast cancer cells: 
uncoupling of aberrant mitosis and apoptosis. Oncogene 2007; 26:2902-2913

18 Nallani SC, Goodwin B, Buckley AR, Buckley DJ, Desai PB. Differences in the induction of cytochrome P450 3A4 by taxane anticancer drugs, docetaxel and paclitaxel, assessed employing primary human hepatocytes. Cancer Chemother Pharmacol 2004;54:219-229

19 Schmittgen TD, Livak KJ. Analyzing real-time PCR data by the comparative C(T) method. Nat Protoc 2008;3:1101-1108

20 Duarte ML, de Moraes E, Pontes E, et al. Role of p53 in the induction of cyclooxygenase-2 by cisplatin or paclitaxel in nonsmall cell lung cancer cell lines. Cancer Lett 2009;279:57-64

21 Fauzee NJ. Taxanes: promising anti-cancer drugs. Asian Pac J Cancer Prev 2011;12:837-851

22 Howe LR. Inflammation and breast cancer. Cyclooxygenase/prostaglandin signaling and breast cancer. Breast Cancer Res 2007; 9:210

23 Kavallaris M. Microtubules and resistance to tubulin-binding agents. Nat Rev Cancer 2010;10:194-204
24 Sprowl JA, Reed K, Armstrong SR, et al. Alterations in tumor necrosis factor signaling pathways are associated with cytotoxicity and resistance to taxanes: a study in isogenic resistant tumor cells. Breast Cancer Res 2012;14:R2

25 Dei A, Bernardini S. Hormetic effects of extremely diluted solutions on gene expression. Homeopathy 2015;104:116-122

26 Bigagli E, Luceri C, Bernardini S, Dei A, Dolara P. Extremely low copper concentrations affect gene expression profiles of human prostate epithelial cell lines. Chem Biol Interact 2010; 188:214-219

27 Pusztai L. Markers predicting clinical benefit in breast cancer from microtubule-targeting agents. Ann Oncol 2007;18(Suppl 12): xii15-xii20

28 Gelmon K. The taxoids: paclitaxel and docetaxel. Lancet 1994; 344:1267-1272

29 Lobert S, Jefferson B, Morris K. Regulation of $\beta$-tubulin isotypes by micro-RNA 100 in MCF7 breast cancer cells. Cytoskeleton (Hoboken) 2011;68:355-362 